UDC 821.124’02.09 Vergilius P. M. 821.124’02.09 Lucretius C. T.

Milica Kisić

Univerzitet u Novom Sadu

Filozofski fakultet

Odsek za istoriju

nekmoli@orion.rs
Originalni naučni rad

primljeno: 27. jun 2011

prihvaćeno: 1. oktobar 2011

\title{
SMRT I USKRSNUĆE MITA: VERGILIJEVO ČITANJE LUKRECIJA*
}

Sažetak: Kroz didaktičko-filozofski spev De rerum natura Lukrecije, između ostalog, nastoji da u potpunosti demistifikuje i ogoli duboko uvrežene mitološke predstave, te da pruži strogo naučno utemeljena objašnjenja za sve prirodne fenomene. Vergilije, pak, iako pod nesumnjivo snažnim uticajem prethodnika, kroz svoje Georgike polemiše sa Lukrecijem oživljavajući „upokojeni““ mit i neretko mu pridajući alegorijsku dimenziju.

Ključne reči: De rerum natura, Georgike, intertekstualni dueli, remitologizacija, realegorizacija.

Čitav Vergilijev spev Georgike može se posmatrati i kao svojevrstan intertekstualni dijalog autora sa Lukrecijevim spevom De rerum natura. Mlađi pesnik neprekidno problematizuje Lukrecijevo racionalističko poimanje sveta i pojedinih prirodnih fenomena, a to najčešće čini direktno suprotstavljajući sopstvene, Hesiodove ili Aratove ideje Lukrecijevim - dakle kreiranjem intertekstualnog duela, ili tako što tendenciozno koristi Lukrecijev jezik izlažući stavove u potpunosti oprečne njegovim učenjima. Na vrlo sličan način Vergilije reaguje i na Lukrecijev tretman mita u De rerum natura.

Lukrecije nam suvo i razložno demistifikuje poreklo mita u dva navrata: u okviru V knjige, kroz diskusiju o postanku religije (V. 1161-1240), i u kontekstu racionalističnog tumačenja fenomena eha u IV pevanju (IV. 571-594). Ljudi su nekada bespomoćno posmatrali nebo i zemlju, bez ikakve mogućnosti da ih razumeju. Potom su vremenom sve neobjašnjive pojave pripisivali božanstvima («ergo perfugium sibi habebant omnia divis tradere», V. 1186), pletući tako, bilo iz straha bilo iz karakteristične ljudske potrebe za pripovedanjem, čitav jedan mitološki korpus koji se prenosio sa generacije na generaciju. Lukrecijeva misija je, naravno, da ljudski rod oslobodi verovanja u bajke, ali on svejedno veoma inteligentno prepoznaje zavodljivost mitološkog jezika kao snažnog psihološkog oružja za postizanje primarnog cilja: nudi radikalno i teško svarljivo poimanje života u 
dopadljivoj i prijemčivoj „mainstream“-ambalaži. Obično koristi dva prepoznatljiva metoda: suprotstavlja mitološku verziju obrazloženja kakvog fenomena atomističkom tumačenju iste pojave, ili primenjuje mitološki jezik pri izlaganju sasvim naučnih stanovišta, a da se nijednom eksplicitno ne poziva na mit. Tako, primera radi, govoreći o elementima vatre i vode, odnosno naizmeničnoj dominaciji jednog od njih u procesu nastanka sveta, Lukrecije gotovo u celosti pripoveda mit o Faetonu, završavajući odeljak rečima:

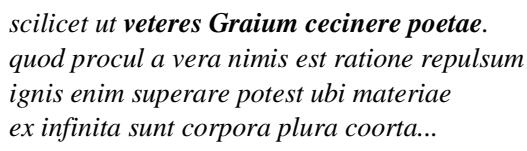

Na trenutak ćemo se odvojiti od započete teme kako bismo primetili da prvi stih citiranog odlomka ima transparentan odjek u, takođe mitološki obojenom, ekscerptu Georgika. Vergilije peva o mitskim konjima Ahila i Marsa služeći se vrlo sličnom frazom:

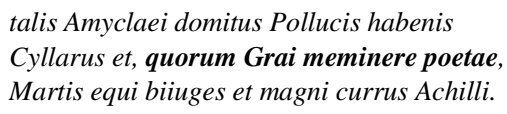

Da se sada vratimo prethodnom toku izlaganja: kako je već naglašeno, Lukrecije u pojedinim slučajevima suptilno angažuje mitološki jezik bez ikakvog konkretnog pomena mita. Tako, u kratkoj istoriji civilizacije u V knjizi De rerum natura, pesnik između ostalog govori o otkriću vatre kao o svojevrsnom daru prirode čovečanstvu: «fulmen detulit in terram mortalibus ignem primitus, inde omnis flammarum diditur ardor» (V. 1091-1092). Potom sunce podučava smrtnike da kuvaju hranu: «cibum coquere... sol docuit» (V. 1102). Jezik navedenih citata kao da igrom asocijacija aludira na mit o Prometeju, čak bi mogao zavesti čitaoca da ova racionalna objašnjenja proglasi alegorijskim tumačenjem pomenutog mita. Međutim, Lukrecije u tom pogledu ostaje nepokolebljiv: jednostavno koristi živopisan i prijemčiv stil kako bi izložio isključivo racionalistički obojen istorijat kulturnog napretka. Koren njegove postavke leži u aksiomu da su mitovi puke izmišljotine. On odbija da predanju pripiše status latentne istine prerušene u odeždu bajke. Mit za Lukrecija nije alegorija koju treba dešifrovati ${ }^{1}$, pre je skalamerija koju valja dekonstruisati - do istine se, po njemu, dolazi tako što se fenomeni iz mitova jednom zasvagda pokoravaju naučnim objašnjenjima.

Vergilije oponira Lukreciju služeći se prilično predvidivim i logičnim metodima: 1) direktnim suprotstavljanjem Lukrecijevog interteksta sasvim drugačijem viđenju; 2) remitologizacijom fenomena koje je on u De rerum natura prethodno demitologizovao; 3 )

\footnotetext{
* Рад је настао као фазни резултат републичког пројекта број 177002 под називом Војвођански простор $y$ контексту европске историје.

${ }^{1}$ Pojedini grčki filozofi, poput Heraklita, Platona ili predstavnika Stoičke škole, zastupaju upravo stanovište koje Lukrecije uporno pobija.
} 
podvlačenjem alegorijske dimenzije mita tamo gde je njegov prethodnik odlučno pobija. Moglo bi se čak ukratko zaključiti da Lukrecije beskompromisno i neumoljivo osuđuje mit na smrt, a potom beskrvnu mitološku avet angažuje kao simulakrum. Vergilije pak uspešno reanimira mit, dodeljujući mu jednu od najzahtevnijih uloga u Georgikama.

\section{Intertekstualni dueli i remitologizacija}

Baš kao što se pitanje etiologije rada u Georgikama problematizuje (i ne razrešava) istovremenim prisustvom naizgled nespojivih mišljenja - hesiodovske nostalgije i Aratove predstave o Jupiteru kao ocu dobročinitelju sa jedne, i Lukrecijeve suvoparno racionalističke istorije civilizacije sa druge strane, tako se problematizuju još neke interesantne teme Vergilijevog speva. Mogućnost ljudi da, čitajući nebeske znake i mene, sa sigurnošću predviđaju vreme pripisana je Jupiterovoj milosti (Ge. I. 351-355), a potom i dodatno rasvetljena kvazinaučnim stilom koji čitaoce odmah asocira na De rerum natura (Ge. I. 415-423). Još zanimljiviji je tretman teme pet klimatskih zona kod dvojice pesnika $^{2}$ :

\footnotetext{
Quod si iam rerum ignorem primordia que sint, hoc tamen ex ipsis caeli rationibus ausim confirmare aliisque ex rebus reddere multis, nequaquam nobis divinitus esse paratam naturam rerum: tanta stat praedita culpa. Principio quantum caeli tegit impetus ingens, inde avidam partem montes silvaeque ferarum possedere, tenent rupes vastaeque paludes et mare quod late terrarum distinet oras. inde duas porro prope partis fervidus ardor assiduusque geli casus mortalibus aufert. quod superest arvi, tamen id natura sua vi sentibus obducat ni vis humana resistat vitae causa valido consueta bidenti ingemere et terram pressis proscindere aratris. (Lucr. V. 195-209)
}

idcirco certis dimensum partibus orbem per duodena regit mundi sol aureus astra. quinque tenent caelum zonae: quarum una corusco semper sole rubens et torrida semper ab igni; quam circum extremae dextra laevaque trahuntur caeruleae, glacie concretae atque imbribus atris; has inter mediamque duae mortalibus aegris munere concessae divum, et via secta per ambas, obliquus qua se signorum verteret ordo.

(Ge. I. 231-239)

\footnotetext{
${ }^{2}$ Joseph Farrell, Vergil's Georgics and the Traditions of Ancient Epic: The Art of Allusion in Literary History, New York - Oxford 1991,179, 180.
} 
Sasvim je očigledno da pesnici ovde na osnovu identičnih podataka donose dijametralno suprotne zaključke - obojica se slažu da je tek mali prostor na zemlji pogodan za život smrtnika, ali dok je to za Lukrecija samo još jedan u nizu neoborivih antiteoloških argumenata, za Vergilija je upravo dokaz o postojanju božjeg proviđenja. Navedeni egzemplar iz Georgika svesno angažuje Lukrecijev jezik i naučni pristup u kombinaciji sa mitološkom interpretacijom istog fenomena. Kao da se izlažu dve ravnopravne istine, a čitaocu prepušta puna mogućnost izbora.

Neki drugi odeljci Georgika mogu pak poslužiti kao dobre ilustracije za metod remitologizacije uzoraka iz De rerum natura. U stihovima I. 61-63, Vergilije nas podseća na Lukrecijevu epizodu o rođenju prvih ljudi ${ }^{3}$ :

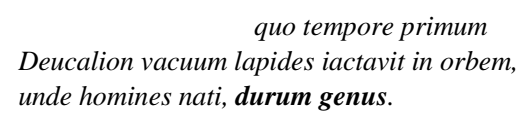

Oba pesnika naglašavaju majčinski princip zemlje - iz njene se plodne utrobe rađaju smrtnici, ali dok Lukrecije na «tellus» gleda kao na apstraktni, hermafroditni i samodovoljni životvorni element, Vergilije uvodi mitsku figuru Deukaliona koji, poput muškog principa, oplođuje Zemlju njenim sopstvenim semenom («lapides»).

Već spomenuti primer odeljka o pet klimatskih zona takođe angažuje metod remitologizacije. Stihovi I. 240-244 direktno oponiraju Lukreciju:

mundus, ut ad Scythiam Riphaeasque arduus arces consurgit, premitur Lybiae devexus in Austros. hic vertex nobis semper sublimis; at illum sub pedibus Styx atra videt Manesque profundi. (Ge. I. 240-243)

at contra nusquam apparent Acherusia templa, nec tellus obstat quin omnia dispiciantur sub pedibus quaecumque infra per inane geruntur.

(Lucr. III. 25-27)

Vergilije najpre demantuje Lukrecijevu tvrdnju da Podzemni svet ne postoji, a potom mu se suprotstavlja i po drugom pitanju. Poznato je da De rerum natura često otvoreno ismeva ideju da bi na «drugoj strani sveta» ${ }^{4}$ uopšte mogli živeti ljudi, dočim Georgike na tu temu pružaju dve mogućnosti: «antipodni» stanovnici zemlje tavore $\mathrm{u}$ večitom mraku, ili kod njih sviće onda kada se kod nas smrkava. Druga opcija je ilustrovana nizom mitoloških predstava - Aurora donosi prvu svetlost («aut redit a nobis

\footnotetext{
${ }^{3}$ W. Y., The Roman Poets of the Augustan Age, Virgil, Oxford 1883, 238.

${ }^{4}$ Zapravo na drugoj Zemljinoj polulopti, što iz današnje perspektive ne deluje nimalo smešno.
} 
Aurora diemque reducit», I. 249), Helije jezdi u vatrenim kočijama («nosque ubi primus equis Oriens adflavit anhelis», 250), a «svetiljke pozne rumeno razgara Veče» («illic sera rubens accendit lumina Vesper», 251). Živopisne mitološke personifikacije svetla nisu tek ornamenti, već i tendenciozan odgovor Lukrecijevom tekstu ${ }^{5}$ :

\begin{abstract}
at nox obruit ingenti caligine terras,
at ubi de longo cursu sol ultima caeli

impulit atque suos efflavit languidus ignis

concussos itere et labe factos aere multo, aut quia sub terras cursum convertere cogit vis eadem, supra quae terras pertulit orbem. Tempore item certo roseam Matuta per oras aetheris auroram differt et lumina pandit, aut quia sol idem, sub terras ille revertens anticipat caelum radiis accendere temptans, aut quia conveniunt ignes...
\end{abstract}

(Lucr. V. 650-660)

Lukrecije ne samo da demitologizuje stvarnost, on impicitno ukazuje i na racionalističko tumačenje etiologije mitova o svetlosti - zora smrtnicima deluje poput svetiljke, a sunce na svom nebeskom putu uistinu podseća na vozara u ognjenim kočijama. Vergilije pak insistiranjem da se mitološke figure percepiraju i ad litteram, kao kakvi izaslanici najviših božanstava, samo ponovo podvlači svoju veru u proviđenje.

Vrlo upečatljiv primer postupka remitologizacije susrećemo i pri kraju I knjige Georgika (I. 466-490). Pesnik nabraja podugačak niz zloslutnih znamenja i prirodnih katastrofa koje su, navodno, usledile neposredno po Cezarovoj pogibiji, tumačeći ih kao nedvosmislene izraze božjeg gneva i crne vesnike novog talasa građanskih ratova. Nije teško pretpostaviti da se istim fenomenima bavio i Lukrecije (posebno u VI pevanju De rerum natura), nastojeći da ih u potpunosti demitologizuje i naučno rasvetli:

1) pomračenje Sunca (V. 751-770)

2) erupcije vulkana (VI. 639-702)

3) zemljotresi (VI. 535-607)

4) poplave (I. 280-294)

5) komete (II. 203-209)

Lukrecije, naravno, uzrok za pomračenje vidi u fizičkim preprekama između Zemlje i Sunca - to može biti Mesec koji direktno zaklanja svetlost, ili kakvo drugo nebesko telo «promičuć nevidno» ${ }^{6}$. Erupcije vulkana se porede sa posve prirodnim procesima upala i povišenom temperaturom u ljudskom organizmu. Pojava zemljotresa opravdana je postojanjem podzemnog reljefa vrlo sličnog onome koji nas okružuje podzemnim rekama, jezerima, pećinama i stenama koje često mogu biti trošne i sklone odronima, te potresima osetnim i na površini Zemlje. Poplave su objašnjene pojačanim

\footnotetext{
${ }^{5}$ W. Y., The Roman Poets of the Augustan Age, Virgil, 246.

${ }^{6}$ Lukrecije, O prirodi stvari, prevela: Anica Savić-Rebac, Beograd 1951.
} 
količinama padavina ili otapanjem snežnih masa sa planina i uzvišenja. Strmoglavo kretanje kometa rasvetljeno je tendencijom nebeskih tela da «po sebi svagda streme naniže kroz prazan prostor» ${ }^{7}$.

Vergilije u narečenom kontekstu oživljava i pojave koje je Lukrecije izričito proglasio pesničkim ili pučkim izmišljotinama:

1) bunari/ kamenje koje krvari (I. 884)

2) gromovi iz vedra neba (VI. 247)

3) aveti, pri čemu doslovno pozajmljuje čitavu frazu od svog prethodnika:

etsi praeterea tamen esse Acherusia templa

Ennius aeternis exponit versibus edens,

quo neque permaneant animae neque corpora nostra

sed quaedam simulacra modis pallentia miris.

(Lucr. I. 120-123)

vox quoque per lucos vulgo exaudita silentis

ingens, et simulacra modis pallentia miris

visa sub obscurum noctis...

(Ge. I. 476-478)

Najinteresantniji za razumevanje postupka remitologizacije čini se odlomak sa opisima vulkanske erupcije:

quotiens Cyclopum effervere in agros

vidimus undantem ruptis fornacibus Aetnam,

flammarumque globos liquefactaque volvere saxa!

(Ge. I. 471-473)

Lukrecije o erupciji Etne govori u dva navrata - I. 722-725 i VI. 680-693. Prvi odeljak pripada svojevrsnom omažu filozofu Empedoklu, a vulkan je tendenciozno personifikovan tako da asocira na mit o Tifeju $^{8}$, te na Prometejevo proročanstvo iz Eshilove tragedije ${ }^{9}$ :

\footnotetext{
${ }^{7}$ Ibid.

${ }^{8}$ Sin Tartara i Geje, najmlađi i najsnažniji gigant sa stotinu zmijskih glava. U svojoj sili i obesti pretio je bogovima da će srušiti nebo i svrgnuti ih sa vlasti. Zevs ga je sažegao munjom, pretvorio mu snagu u prah i pepeo, a zatim ga zatočio planinom Etnom. Zato, po legendi, iz Etne kuljaju dim i oganj: to i dalje besni sapeti Tifon.

${ }^{9}$ Eshil, Okovani Prometej, preveli Koloman Rac i Nikola Majnarić, Beograd 1988, 18:

Sad leži ondje blizu tijesna morskoga,

a tiskom tišti njega Etne gore dno,

a navrh vrha sjedi, gvožđe kuje bog

Hefesto; tu će jednom vatre potoci

provalit, gladnim ždrijelom ravna polja će

tad Sicilije krasne, rodne proždirat

bujicom žarkom strašne bure ognjene.

Da, takvim jedom Tifej će uskipjet sav!
} 
hic Aetnaea minantur

murmura flammarum rursum se colligere iras,

faucibus eruptos iterum vis ut vomat ignis

ad caelumque ferat flammae fulgura rursum.

(Lucr. I. 722-725)

Podvučeni delovi teksta usmeravaju pažljivijeg čitaoca da erupciju vulkana doživi kao pretnju i napad upućen prvenstveno nebu («minantur... ut vomat ignis ad caelum»), a izbor i ponavljanje priloga («rursum... iterum... rursum») sugerišu da se takav atak u prošlosti već zbio. Nije, dakle, neobično što se pred našim očima Etna živo transformiše u gigantskog Tifeja i što stičemo utisak da se svakog trenutka može obistiniti Prometejevo zloslutno proročanstvo. Ovakve i slične aluzije nisu retkost - Epikur se (baš kao ovde posredno Empedokle) u De rerum natura često dovodi u vezu sa mitskim divovima ${ }^{10}$. Međutim, dok su giganti u antici obično nosili negativna simbolična značenja poput rušilačkih sila prirode, varvarstva ${ }^{11}$ ili oholosti, Lukrecije ih kroz svoje suptilne mitološke aluzije slika kao heroje i plemenite buntovnike. Epikur nas podseća na Prometeja ili Tifeja koji se neustrašivo ustremio na Olimp i religiju.

Drugi opis Etne pak, sasvim suvo i bez simboličke dimenzije, racionalizuje legende o kiklopima. Pesnik koristi jasan aluzivni marker u sprovođenju postupka demitologizacije:

Nunc tamen illa modis quibus inritata repente

flamma foras vastis Aetnae fornacibus efflet,

expediam. primum totius subcava montis

est natura, fere silicum suffulta cavernis.

(Lucr. VI. 680-683)

Pokušava da nam kaže da živi vulkan uistinu može zaličiti smrtnicima na pećnicu u kovačkoj radionici, pa stoga nije neobično da su takvoj slici svojevremeno pridodati i izmišljeni jednooki kovači.

Vergilije, po svemu sudeći, kombinuje oba Lukrecijeva odeljka. Fraze «Cyclopum agros» i «fornacibus» ponovo pretvaraju običan vulkan u kovačke peći kiklopa, a njegova erupcija sluti rušilaštvo i haos iz mita o Tifeju (kao da se obistinilo Prometejevo proročanstvo). Uz to, gigant u Georgikama gubi svoj viteški sjaj iz De rerum natura i nanovo postaje simbol destrukcije ${ }^{12}$, ovoga puta i nesreće građanskog rata.

\footnotetext{
${ }^{10}$ Epikur napada nebo (Lucr. I. 62-79) ili poređenje Epikurovog pohoda na religiju sa pohodom giganata na Olimp (Lucr. V. 113-121).

${ }^{11}$ Primera radi, scene Gigantomahije u grčkom vaznom slikarstvu obično simbolično odslikavaju borbe Helena i varvara.

${ }^{12}$ Tifej se u Georgikama i eksplicitno pominje u negativnom kontekstu: nabrajajući povoljne i nepovoljne dane u mesecu, Vergilije pominje peti kao rođendan «giganta groznog Tifeja», te stoga izrazito baksuzan za obavljanje bilo kakvog posla (Ge. I. 277-279).
} 


\section{Realegorizacija}

Svi mitovi kojih smo se do sada dotakli imali su veze sa elementarnim prirodnim fenomenima, pa su u De rerum natura bili predmet sasvim očekivane demitologizacije kroz pružanje čvrstih i naučno zasnovanih argumenata. Postoje, međutim, i oni koje Lukrecije uopšte ne uzima ozbiljno u obzir - mitove o nadnaravnim metamorfozama i hibridnim bićima pesnik beskompromisno odbacuje kao besmislice. Kroz spev se provlači jasna ideja da se biljne i životinjske vrste na zemlji, sa svim svojim osobenostima, nisu znatnije menjale od postanka sveta:

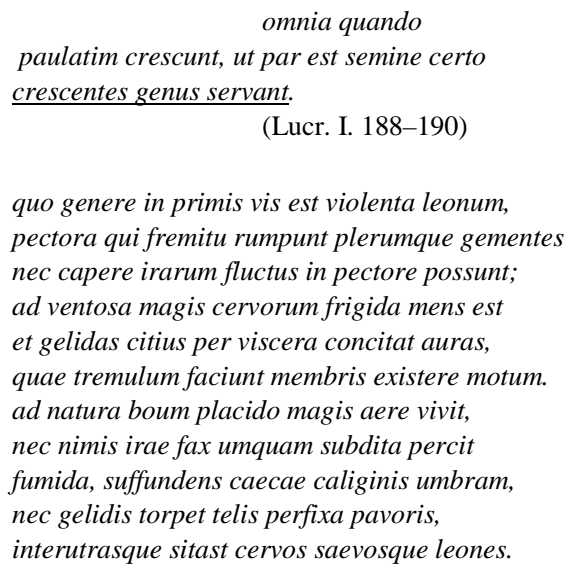

quo genere in primis vis est violenta leonum, pectora qui fremitu rumpunt plerumque gementes nec capere irarum fluctus in pectore possunt; ad ventosa magis cervorum frigida mens est et gelidas citius per viscera concitat auras, quae tremulum faciunt membris existere motum. ad natura boum placido magis aere vivit, nec nimis irae fax umquam subdita percit fumida, suffundens caecae caliginis umbram, nec gelidis torpet telis perfixa pavoris, interutrasque sitast cervos saevosque leones.

(Lucr. III. 296-306)

nihil tamen est signi mixtas potuisse creari inter se pecudes compactaque membra animantum, propterea quia quae de terris nunc quoque abundant herbarum genera ac fruges arbustaque laeta non tamen inter se possunt comlexa creari, sed res quaeque suo ritu procedit, et omnes foedere naturae certo discrimina servant.

(Lucr. V. 918-924)

Hibridna bića poput kentaura ili himere nikako ne mogu postojati - ljudi i konji se do te mere fiziološki razlikuju da bi njihova kombinacija bila sasvim neizvodljiva. Kada bi svi atomi bili kadri da se, bez obzira na svojstva, međusobno spajaju, pojedine vrste bi se javljale u nezamislivim bojama - gavranovi bi bili beli, a labudovi crni:

\footnotetext{
Praeterea quoniam non certis certa figuris est natura coloris et omnia principiorum formamenta queunt in quovis esse nitore, cur ea quae constant ex illis non pariter sunt omne genus perfusa coloribus in genere omni? conveniebant enim corvos quoque saepe volantis ex albis album pinnis iactare colorem,
} 
et nigros fieri nigro de semine cycnos

aut alio quovis uno variove colore.

(Lucr. II. 817-825)

Lukrecije, dakle, u potpunosti obesmišljava mitove o hibridnim bićima i metamorfozama, ignorišući pritom tradicionalno shvatanje da bi se oni mogli tumačiti na alegorijskom nivou. Vergilije pak kroz Georgike u više navrata koristi takve mitove upravo ističući njihovu duboku alegoričnost.

Baš kao što u III knjizi speva, u poglavlju o kugi, Vergilije tendenciozno humanizuje životinje, zamagljujući tako strogo ucrtana razmeđa ljudskog i životinjskog sveta, tako se u centralnom delu iste knjige odvija posve antipodan proces sa identičnim efektom. Otvoreno izazivajući Lukrecijevu postavku o svemoći razuma, Georgike pevaju o razornom dejstvu strasti - amor je neumoljiva sila koja animalizuje smrtnike, pa čak i bogove. Prožimanje sfera ljudi i životinja ovde je dodatno naglašeno pozivanjem na mitove o čudesnim metamorfozama. Oslanjajući se na tradiciju po kojoj se čuvena Kirkina transformacija Odisejevih saputnika u svinje posmatra kao brutalno odslikavanje banalne i isključivo karnalne muške želje, Vergilije aludira na mitove o Saturnu i Filiri ${ }^{13}$, odnosno Iji i obadu ${ }^{14}$, a sve u kontekstu koji ih povezuje upravo sa idejom o dehumanizujućoj moći strasti. Saturnov preobražaj u konja navodi se naizgled prirodno, u okviru spiska sjajnih mitskih ždrebaca:

\section{talis et ipse iubam cervice effundit equina coniugis adventu pernix Saturnus, et altum Pelion hinnitu fugiens implevit acuto.}

(Ge. III. 92-94)

Humoreskna minijatura boga koji u četvoronožnom obličju izmiče gnevu ljubomorne supruge ciljano podseća čitaoce na odeljak gde se o nesavladivoj snazi libida govori u daleko ozbiljnijem tonu - na epizodu strašću zaslepljenog Leandra ${ }^{15}$ i njegovom poređenju sa razjarenim pastuvom ${ }^{16}$ :

quid iuvenis, magnum cui versat in ossibus ignem

\footnotetext{
${ }^{13}$ Filira je kćer Okeana i Tetide, a majka kentaura Hirona. Zaljubljeni Saturn se, prema jednoj verziji, sjedinio sa njom u vidu pastuva, pa je njihov porod stoga imao ljudski trup i noge konja. Drugi pripovedaju da se bog sa Filirom sjedinio na jednom malenom ostrvu, ali ih je tu iznenadila Reja. U strahu od supruge, Saturn se preobrazio u dugogrivog pastuva. Filira je umakla u Tesaliju, gde je nešto kasnije rodila Hirona.

${ }^{14}$ Ija je legendarna argivska princeza i ljubavnica Zevsova. Bog ju je preobrazio u belu kravu kako bi je zaštitio od ljubomorne supruge. Hera je svejedno prozrela Zevsovo lukavstvo i zatražila od njega kravu na poklon. Ovaj joj je, iz osećaja krivice zbog nevere, ispunio tu želju, a Hera je životinju iz predostrožnosti poverila na čuvanje stookom divu Argu. Kada je, po Zevsovom nalogu, Hermes usmrtio Ijinog zastrašujućeg čuvara, Hera je na nju poslala ljutog obada da joj siše krv i goni je iz mesta u mesto. Pošto je obišla čitav svet, sasvim pomućenog uma, Ija je konačno našla utočište u Egiptu, gde joj je Zevs vratio nekadašnje obličje.

${ }^{15}$ Mladić iz grada Abida na Helespontu koji se zaljubio u Hero, sveštenicu boginje Afrodite, iz grada Sesta na suprotnoj obali mora. Uprkos preprekama i opasnostima, svake je noći preplivavao Helespont da bi se našao u zagrljaju voljene. Ona je palila svetlo na svojoj kuli kao dogovoreni putokaz draganu. Jedne noći vetar je ugasio svetlost, a more sutradan nasukalo Leandrovo beživotno telo. Neutešna Hero se sa kule bacila u ponor.

${ }^{16}$ Pastuv, kao nosilac najsnažnijeg i najbrutalnijeg libida, igra u Georgikama ulogu univerzalnog simbola pogubnog dejstva nekontrolisanog seksualnog nagona na životinje, ali i na ljude.
} 
durus amor? nempe abruptis turbata procellis

nocte natat caeca serus freta; quem super ingens

porta tonat caeli, et scopulis inlisa reclamant

aequora; nec miseri possunt revocare parentes,

nec moritura super crudeli funere virgo.

(Ge. III. 258-263)

Činjenica da nas na konkretan mit upućuje tek fusnota ${ }^{17}$, Leandru pripisuje paradigmatičnu ulogu - on simbolično predstavlja sve mlade muškarce i samo je karika u nizu životinjskih vrsta koje na isti način podležu telesnoj želji («in furias ignemque ruunt: amor omnibus idem.», Ge. III. 145). Lukrecijeva misao o superiornosti ljudi jasno se demantuje - libido poseduje snagu da raščoveči smrtnike, pa i bogove.

Aluzija na mit o Iji na vrlo sličan način povezuje karnalnu strast sa gubitkom ljudskog identiteta. Preobražaj se u ovom slučaju intenzivira i odvija u dva sloja - ona ne gubi samo obličje žene, već i zdrav razum:

est lucos Silari circa ilicibusque virentem

plurimus Alburnum volitans, cui nomen asilo

Romanum est, oestrum Grai vertere vocantes, asper, acerba sonans, quo tota exterrita silvis diffugiunt armenta, furit mugitibus aether concussus silvaeque et sicci ripa Tanagri. hoc quondam monstro horribilis exercuit iras Inachiae Iuno pestem meditata iuvencae.

(Ge. III. 146-153)

Vergilije ovde postiže suptilnu alegorijsku poentu jezičkom igrom na dva nivoa baš kao što naizgled naivni i duhoviti prizor Saturna preobraženog u konja priziva u sećanje čitalaca Leandrovu ljubavnu pomamu, tako nas i priča o obadu vraća na tematiku bespoštednog dejstva strasti na ljude i životinje. Pesnik pravi namerne autocitate: «furit mugitibus aether» (Ge. III. 150) asocira na «furias» (III. 244) i «furor» (III. 266). Potom se i amor i napad obada povezuju sa toplijim vremenom i višim temperaturama - «nam mediis fervoribus acrior instat» (III. 154) ₹ «vere magis, quia vere calor redit ossibus» (III. 272), oboje teraju žrtve u raspomamljeni beg - «quo tota exterrita silvis diffugiunt armenta» (III. 149-150) ₹ «saxa per et scopulos et depressas convallis diffugiunt» (III. 276-277) i predstavljaju opasnosti od kojih pastir valja da zaštiti stado - «arcebis gravido pecori» (III. 155) $\approx$ «Venerem et caeci stimulos avertere amoris» (III. 210).

Drugi nivo jezičke igre podrazumeva, za osnovnu temu teze još zanimljiviju, komunikaciju oba razmatrana odeljka sa tekstom De rerum natura. I u jednom i u drugom slučaju Vergilije suprotstavlja mitološke aluzije frazama koje njegov prethodnik ispisuje u okviru antimitoloških polemika. Da se podsetimo: neposredno pre pomena Saturna preobraženog u pastuva, pesnik se služi izrazom «quorum Grai meminere poetae» (III. 90), za koji smo već konstatovali da gotovo doslovno preslikava Lukrecijevo «ut veteres

\footnotetext{
${ }^{17}$ Ime se ne pominje eksplicitno, ali je jasno o kome je reč, a u samom tekstu Georgika postoji i docnije pridodata fusnota sa objašnjenjem.
} 
Graium cecinere poetae» (V. 405) iz odlomka gde se demitologizuje predanje o Faetonu. Na vrlo sličan način, obad je u priči o Iji opisan kao «asper, acerba sonans» (III. 149), što neodoljivo podseća na Lukrecijev ironični osvrt na mit o Heraklovim podvizima iz uvoda V knjige De rerum natura, gde je hesperidski zmaj skiciran rečima «asper, acerba tuens» $(\mathrm{V} .33)^{18}$.

Pomenuti intertekstualni dijalog svedoči u prilog teoriji da Vergilije tendenciozno oživljava upravo tip mitova koje je Lukrecije svojevremeno obesmislio ili odbacio. I ne samo da ugaslim mitološkim iskrama vraća nekadašnji plam - pesnik im kroz pridavanje alegorijske dimenzije na izvestan način daruje besmrtnost: predanja o Saturnu i Iji će čitaocima bilo koje epohe biti vanvremeni simbolični podsetnici da amor sa lakoćom može probuditi sapetu zver u svakome.

Izvori i literatura:

Izvori u originalu i srpskom prevodu:

T. Lucreti Cari, De rerum natura, recensuit, emendavit, supplevit Hermannus Diels, Berolini, 1923. Vergil, Georgics, edited by Richard F. Thomas, Cambridge, 1998.

Eshil, Okovani Prometej, preveli Koloman Rac i Nikola Majnarić, Beograd, 1988.

Lukrecije, O prirodi stvari, prevela: Anica Savić-Rebac, Beograd, 1951.

Literatura:

Srejović Dragoslav, Cermanović Aleksandra, Rečnik grčke i rimske mitologije, Beograd, 1992.

Farrell Joseph, Vergil's Georgics and the Traditions of Ancient Epic: The Art of Allusion in Literary History, New York - Oxford, 1991.

Gale Monica, Virgil on the Nature of Things - Influence, Allusion, Intertextuality, www. assets. cambridge. org.

Sellar W. Y., The Roman Poets of the Augustan Age, Virgil, Oxford, 1883.

\footnotetext{
${ }^{18}$ Monica Gale, Virgil on the Nature of Things - Influence, Allusion, Intertextuality, www. assets. cambridge. org.
} 
MILICA KISIĆ

\title{
DEATH AND RESURRECTION OF THE MYTH: VIRGIL'S READING OF LUCRETIUS
}

\begin{abstract}
Summary
Virgil's didactic poem Georgike was written, among other things, as a kind of an intertextual dialogue with works of the poet's predecessors and the established masters of this subgenre - Hesiod, Arat, and Lucretius above all. The paper was specifically focused on the controversy between Virgil and Lucretius on clarifying the everyday's natural phenomena by engaging traditional mythological matrix: like writing the verses on the palimpsest, Virgil adds a new layer of meaning over already "given" Lucretius's text, using fully expected methods of the intertextual "duel", demythologization and dealegorization, thus reviving the myth which was tendentiously demystified and removed by his model.
\end{abstract}

Keywords: De Rerum Natura, Georgike, intertextual duels, demythologization, dealegorization. 